\title{
Challenging partial intentionalism
}

\author{
Hans Maes University of Kent, UK
}

\begin{abstract}
Paisley Livingston claims that an artist's intentions are successfully realized and hence determinant of the meaning of a work if and only if they are compatible and "mesh" with the linguistic and conventional meanings of the text or artefact taken in its target or intended context. I argue that this specific standard of success is not without its difficulties. First, I show how an artist's intention can sometimes be constitutive of a work's meaning even if there is no significant meshing between the artist's intention and his work. Secondly, I argue against the claim that the artist's intentions need to be compatible with the linguistic and conventional meanings of a text. Thirdly, I discuss a case that creates a particular puzzle for Livingston since the intentions of the artist concerned are not successfully realized, though they are compatible and mesh with all the relevant data. I conclude my paper by suggesting a solution to this puzzle.
\end{abstract}

The role of intention in the interpretation of art has been a topic of lively debate in analytic aesthetics. Absolute intentionalism holds that a work's meaning and the artist's intentions with regard to the work's meaning are logically equivalent. Absolute anti-intentionalism, by contrast, claims that the artist's intentions are never relevant with regard to a work's meaning. Both extreme positions still have advocates today, but most participants in the debate seem convinced that an intermediary position is needed, explaining how intentions are relevant but not solely determinant for work meaning. Several moderate accounts have been proposed, but so far no consensus has been reached. Moderate actual intentionalists contend that the intentions relevant to the interpretation of a work of art are the actual intentions of the pertinent artist, whereas hypothetical intentionalists claim that what is relevant for interpretation is the best hypothesis, formulated by an appropriate audience, of the actual artist's intentions. A third account, fictionalist intentionalism, holds that interpreters need not concern themselves with the actual artist and should simply pretend that the intentions expressed in the work are expressed by a fictional or postulated artistic persona.

One of the most noteworthy recent contributions to this debate is Paisley Livingston's Art and Intention (2005) in which an elaborate new version of moderate actual intentionalism is delineated and defended. He calls this view 'partial intentionalism', his account of which is complemented by arguments against hypothetical and fictionalist intentionalism. On both levels, Livingston does an outstanding job. His account of the role of intention in interpretation is one of the most sophisticated and convincing to date, and his critical evaluation of rival accounts is both fair and thorough. Livingston has helped to make moderate actual intentionalism the best

\section{Keywords}

intention

interpretation

intentionalism

jokes

cartoon

Livingston 
defended position in the debate, though he has not dispelled all of the difficulties with this view. My aim in this paper is to bring some of these difficulties to the fore. In the process, I also aim to show that, despite the current antagonism, some insights and aspects of rival accounts, especially hypothetical intentionalism, are worth keeping and can be of use to the actual intentionalist. But first I will introduce the aspect of Livingston's theory to which my comments are most relevant.

I.

Moderate actual intentionalists claim that the artist's intentions, if successfully realized, are partly constitutive of some of the work's meanings. 'A key issue', therefore, 'hinges on the nature of the "success" condition to be weighed on artists' intentions' (Livingston 2005: xiii). When exactly are intentions successfully realized and hence determinant of the meaning of a work? Different proponents of moderate actual intentionalism have answered this question in different ways.

According to Gary Iseminger, the meaning of the work 'is the meaning compatible with the text [original emphasis] that the author intended' (Iseminger 1996: 321). If one discovers that the author had some meaning in mind that is incompatible with the text, one must conclude that he has failed to realize his intention. However compelling, this 'compatibility view' seems to have some undesirable consequences. Imagine, Livingston says, the Japanese novelist Soseki giving an interview in which he sincerely and accurately reveals his intention that the three main characters in his trilogy of novels, Sanshiro (1908), And Then (1909) and The Gate (1910), were meant to be the successive appearances of a Martian in disguise. This Martian storyline seems 'tacked on' and extraneous. Most if not all readers would have failed to think of it had they not read the interview. Still, such a reading is compatible with the textual evidence. Would we not in this particular case be justified in denying the correctness of the Martian reading of the story? 'Clearly', Livingston writes, 'if no features of the novel's characterization resonate with the Martian intention, the latter could be discounted' (Livingston 2005: 155). So, 'being consistent or compatible with the data' will not suffice as a success condition. A more substantial criterion is needed.

One such criterion can be found in Robert Stecker's book, Interpretation and Construction. 'An utterance does mean what a speaker intends', Stecker claims, 'if the intention is apt to be recognized in part because of the conventional meaning of the words used, or of a context that extends those meanings' (Stecker 2003: 14). In other words, intentions do not merely have to be compatible with the data, they also have to be 'capable of uptake' by properly prepared receivers.

Livingston, though not unsympathetic to a proposal of this sort, cannot subscribe to it because '[s]ometimes the author's semantic intentions are less limited than the meanings a reader may be able to dream up on the basis of the text and other background evidence. Sometimes interviews and diaries open up all sorts of wonderful undiscovered meanings' (Livingston 2005: 164). An uptake view of work meaning cannot take this into account.

Thus, the question remains: when exactly are intentions successfully realized in a work? With Stecker's uptake condition being too strong and Iseminger's compatibility condition too weak, Livingston proposes a via 
media with the default standard of success "being simply that the intentions are compatible and "mesh" with the linguistic and conventional meanings of the text or artefact taken in its target or intended context' (Livingston 2005: 155). The crucial term in this formula is 'mesh', but Livingston is somewhat evasive about its precise meaning. Speaking about the Soseki example, he only says that the partial intentionalist would accept the new reading if the peculiar authorial clue resonates with or 'opens up previously undetected connotations of various features of the text' (Livingston 2005: 155). Later in the book, he tries to be more specific:

Meshing... means 'be consistent with', but also carries the implication of a stronger condition involving relevance and integration: if there is a sense in which an extraneous hypothesis is consistent with data, but bears no meaningful, integrative relation with them, we would say that the two do not mesh.

(Livingston 2005: 199)

And if the artist's intentions do not mesh with the explicit features of the text or artefact, they cannot be constitutive of work meaning. What I want to show now is that Livingston's own proposal for a standard of success is not without its problems and difficulties.

II. Here we see a little girl's scribbled drawing:'

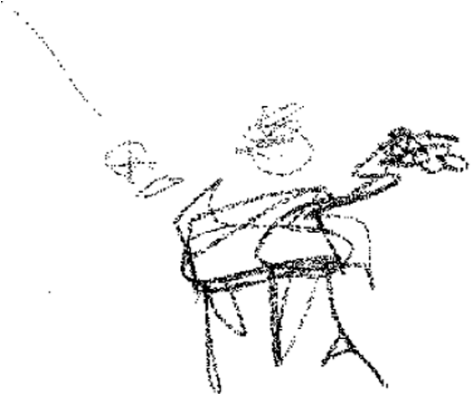

Figure 1.

If she tells us that this is a drawing of a dog, we would probably accept her explanation and believe that that is what the drawing is about. But if she tells us that the drawing represents her father (with one arm raised), we would also accept that explanation and believe that that is what we are looking at (the fact that there seem to be three legs and no neck wouldn't bother us too much). Or suppose she tells us that it's the front yard, or a piano, or grandma's house: in all these cases we would probably regard her intention as partly determinant of what the drawing is about. ${ }^{2}$ In other words, we seem willing to take seriously almost any sincere explanation the young artist may provide, independent of how well that explanation meshes with the features of her drawing.

There is an easy explanation for this, the partial intentionalist might reply. We accept almost any (sincere) explanation by the little girl simply
1. Reduced in size. Many thanks to my little niece Nina for her kind permission to reproduce her splendid artwork.

2. I am not claiming that the drawing depicts a piano just because the child had the intention to depict a piano. Richard Wollheim (among others) has argued convincingly that intention is not a sufficient condition for depiction (Wollheim 1987). I do think, however, that the child's intention determines what the drawing is about. So, this is a claim about meaning or representation in the broad sense rather than a claim about depiction or pictorial representation. 
3. This point is nicely demonstrated, in a larger context, by conspiracy theories. If enough effort is put into it, conspiracy theorists will always manage to find some 'revealing' connections between events that are totally unrelated.

4. The wall-texts can be found on the website of Tate Modern (http:// www.tate.org.uk/ servlet/ViewWork? workid=27008). because almost any explanation would mesh sufficiently with the totality of evidence. However, taking this line seems to imply giving up the idea that 'to mesh with' means more than just 'to be compatible with'. Recall that Livingston's success condition carries 'the implication of a stronger condition involving relevance and integration'. Just what that might mean is illustrated in the final chapter of Art and Intention, with the example of István Svabó's film Meeting Venus (1991). Various features of this film do not really integrate or fit with Svabó's intention to show that the redemptive force of Tannhäuser arises from the sheer excellence of the music. So, Livingston concludes, there is no sufficient meshing. However, the same is obviously true in the example of the child's drawing. Various elements of the drawing do not fit with, say, the little girl's intention to draw her father (three legs, no neck). Should we conclude in this case as well that there is no sufficient meshing and thus reject the child's account of her own drawing? As I have said, we seem inclined to do the opposite. Yet, if there is sufficient meshing here, then why not in Meeting Venus; and how then defend the claim that 'to mesh sufficiently with' means more than just 'to be compatible with'?

The partial intentionalist is faced with a dilemma. If he decides to interpret the meshing condition loosely, for instance by stating that the artist's intentions mesh sufficiently with the data if they reveal new connotations or connections between various features of the work, it will not do the work it was meant to do, viz. blocking 'tacked on' hypotheses like the Martian storyline in the Soseki example. For even the most extravagant hypothesis will prove revealing in this sense, if only enough effort is put into it. ${ }^{3}$ On the other hand, if the meshing condition is interpreted more narrowly, as Livingston seems to do in his discussion of Meeting Venus, it will prove too restrictive, excluding intentions that we would normally regard as constitutive of a work's meaning. The example of the little girl's drawing illustrates this.

One might object to this particular example, however, on the grounds that conclusions regarding 'child art' have no relevance for 'real art'. But this manoeuvre is bound to fail as it is not so hard to come up with parallel cases from the realm of 'real art'. Consider some of Joseph Beuys' works where the connection between the displayed objects and the intended meaning is no more significant than the connection between the little girl's drawing and her intention to draw her father. For example, we know from interviews and direct statements of the artist that in Lightning with Stag in its Glare (1985) a large bronze triangle was meant to embody the energy of a powerful flash of lightning, an iron cart was meant to represent a goat and strange shapes on the floor were intended as 'primordial creatures' referring to natural energies of the earth. Unless 'to mesh with' is interpreted so broadly that it means no more than just 'to be compatible with', it seems absurd to say that the artist's intentions mesh quite well with the objects on display. Nevertheless, the curators of the exhibition at the Tate Modern, where this work was exhibited in 2006, accepted Beuys' intentions as constitutive of the work's meaning. For the wall-text that accompanied the work, they just took over the artist's own explanation: 'The cart represents a goat, and the clods of bronze on the floor are primordial creatures. A small compass, mounted on top of a box, is another reference, with the lightning flash itself, to the natural energies of the earth'. 4 
III.

The claim, that for an intention to be constitutive of work meaning it needs to mesh with the totality of evidence, is not unproblematic. But what about the 'weaker' and apparently uncontroversial claim that the artist's intentions need to be compatible with the totality of evidence?

Imagine a waiter pointing to an insect visibly floating in your soup and saying 'There's a fly in your suit'. It is obvious that he meant to say that the fly is in your soup, but that is not what he actually said. The easily recognizable intention of the waiter does not determine the meaning of his utterance because it is incompatible with the linguistic and conventional meanings of the words. As Stecker (2003), to whom I owe this example, puts it, the waiter fails to say what he intended to say because 'soup' is neither among the literal meanings of the word 'suit', nor has an appropriate context been established that gives the word 'suit' this extended meaning.

But suppose we modify the example a bit. Imagine a waiter pointing to an insect visibly floating in your soup and saying 'There's a fly in your floup'. Again, the waiter intended to say that there is a fly in your soup, but that is not what he actually said. What did he say, then? What is the meaning of the utterance: 'There's a fly in your floup'? According to Stecker (and Livingston), 'if the speaker's intention is not successful, the meaning is determined by convention and context at the time of utterance' (Stecker 2004: 14). However, 'floup' does not have a conventional meaning. It is not a proper English word. And while some philosophers would argue that in the context of that specific conversation 'floup' just means 'soup', Stecker and Livingston do not take this line. Thanks to the context, the hearer may come to understand that the waiter wants to say something about the soup, but 'this understanding does not imply that the speaker has said what he intends to say or that his utterance means what he intends to communicate' (Stecker 2004: 13). But should we conclude then that the waiter's utterance was completely meaningless? Or should we perhaps conclude, with Iseminger, that there simply is no utterance here (Iseminger 1996: 322)? I must admit I'm not entirely comfortable with either conclusion.

Whatever conclusion we reach in this admittedly banal example will have important implications for less banal cases in art and literary interpretation. For there is an interesting parallel between the waiter's strange use of vocabulary and the idiosyncratic use of vocabulary by modernist poets and novelists. In both cases, the intended meaning is (more or less) clear to the appropriate public, but not compatible with the meaning of the wordsequence produced. When James Joyce writes about 'Dyoublong' he is of course referring to Dublin but also hinting at the phrase: 'Do you belong?'5 Strictly speaking, however, this intended meaning is not compatible with the linguistic and conventional meaning of the text. 'Dyoublong' simply doesn't have a conventional meaning. Or what to think of sentences like: 'Why do I am alook alike a poss of porter pease?' where Joyce wants us to think of Piesporter wine, a request for a pint of porter, please, and the expression 'as like as two peas' - all at the same time. Should we say that this is a meaningless utterance? Or should we say, following Iseminger, that since the word-sequence is without conventional meaning 'we typically do not have an utterance (or work) but rather a failure or a (nonverbal) joke of some sort' (Iseminger 1996: 322). Surely not.
5. I borrow this and also the next example from Davidson's 'James Joyce and Humpty Dumpty' published in Truth, Language, and History (Davidson 2005). 
IV.

Gary Larson's cartoon series The Far Side is widely known. Almost all of these cartoons are very funny but occasionally there is a cartoon that has a different effect on people. Take the notorious 'Cow Tools' cartoon (Larson 1989: 156). It displays a cow standing next to a workbench with tools that look rather primitive. People were just puzzled by the cartoon. After 'Cow Tools' appeared in newspapers in 1982, Larson got hundreds of letters from people wanting to know the meaning of this cartoon, two of which were reprinted in an anthology published on the tenth anniversary of The Far Side:

Enclosed is a copy of the 'Cow Tools' cartoon. I have passed it around. I have posted it on the wall. Conservatively, some 40-odd professionals with doctoral degrees in disparate disciplines have examined it. No one understands it. Even my 6-year-old cannot figure it out... We are going bonkers. Please help. What is the meaning of 'Cow Tools'? - Reader, Texas

I represent a small band of Fellows from every walk of American Life, who have been drawn together by a need to know, a need to understand... [we] have been brought together by the absolute certainty that your cartoon captioned 'Cow Tools' means something. But, as this letter signifies, just what it might mean has escaped us. - Reader, California

(Larson 1989: 157)

In the anniversary anthology, Larson answers the desperate pleas of his readers. One day, he explains, he recalled an anthropology course he had taken in college and how he learned that although man used to be defined as 'the only animal that made and shaped tools', researchers had discovered that certain primates and even some bird species did the same thing. Almost as a matter of course, Larson says, he began thinking about his favourite animals, cows, and what if they, too, were discovered as toolmakers. This unlikely scenario struck him as absurdly funny. So he imagined, and subsequently drew, a cow standing next to her workbench, proudly displaying her primitive 'hoofiwork'.

Reading this explanation, it's natural to think: 'So that's what "Cow Tools" is about'. I assume that's how most readers would react. Now, if this assumption is correct, it may count as strong evidence against hypothetical intentionalism and in favour of actual intentionalism. For instead of sticking with our best hypothesis of what this cartoon is about - whatever that hypothesis may be - we do not hesitate to accept Larson's own explanation. In fact, the readers' letters themselves seem to speak in favour of actual intentionalism. The hypothetical intentionalist claims that 'direct authorial pronouncements of meaning can be set aside by the reader devoted to the central job of interpretation' (Levinson 1996: 208), but the letters show how readers devoted to the central job of interpretation expressly desire authorial pronouncements of meaning. They are 'absolutely certain' that the cartoon means something and that Larson is in a position to help them out.

Still, 'Cow Tools' also raises a problem for Livingston's partial intentionalism. Moreover, the cartoon allows me to highlight a valuable aspect of hypothetical intentionalism that is worth retaining. But before I get to that, I want to draw attention to a minor, perhaps only terminological, issue. 
(i) Chapter six of Livingston's book carries the title 'Intention and the Interpretation of Art' and this expresses perfectly what the debate in aesthetics is about: the role of intention in the interpretation of art. However, when we think of 'Cow Tools' and how we arrive at the meaning of this cartoon, it seems that interpretation has very little to do with this. As several participants in the debate have stressed, if one finds out the meaning of a word by looking it up in a dictionary, one is not interpreting (Davies 2006: 112; Stecker 2004: 4). Similarly, one could say that, if one finds out the meaning of a cartoon or a work of art by reading a catalogue or anthology, one is not interpreting either. ${ }^{6}$

If this is so, then perhaps we should say that the difference between the actual and the hypothetical intentionalist's response to 'Cow Tools' (and similar cases in art), is not a difference in interpretation. To be sure, the actual and hypothetical intentionalist end up disagreeing about the meaning of the cartoon, but that is not because of a significant difference in interpretive activity, but rather because the actual intentionalist accepts that the artist's clarification of his own intention can put an end to the interpretive quest for the work's meaning, in much the same way as a dictionary can put an end to the search for a word's meaning.

(ii) Larson's elucidation gives us a better understanding of the cartoon, but I doubt that many people will actually laugh once they know the intended meaning. This seems true of cartoons and jokes in general. If we don't 'get' a joke, someone may explain it to us, but the explanation will rarely result in spontaneous laughter. Thus, articulating the point of a joke not only puts an end to interpretation, but also, characteristically, puts a damper on the effect of the joke. The two even seem to be connected: there is no effect because there is no interpretation. Let me clarify this further.

Although jokes generally take the form of a riddle or a short story, there is a feature that distinguishes them from 'ordinary' riddles or short stories, namely the punchline. As Noël Carroll points out,

a punchline is not simply a matter of neatly answering the question posed by a riddle nor of drawing all the storylines of a narrative to a summation. Rather, the punchline concludes the joke with an unexpected puzzle whose solution is left to the listener to resolve.... What the listener must do at the end of a joke is to provide an interpretation, i.e., to make sense of the last line of the text in light of the salient elements of the preceding narrative or riddle.

(Carroll 1991: 286)

Precisely because the listener himself has to come up with an interpretation to solve the puzzle of the last line, the solution will be all the more striking to him (hence the 'punch' of the punchline). If, by contrast, the listener is unable to solve the puzzle himself, and someone else has to explain it, that effect - things falling suddenly into place producing spontaneous laughter will largely disappear.

This analysis also applies to cartoons - just think of The Far Side where the caption often fulfils the role of the punchline, creating a puzzle that the reader needs to solve. Likewise, there are clear cases of art-with-a-punchline. Duchamp's LHOOQ (1919) is a famous example. Or take the film Citizen Kane (1941) and its central plotline, the search for the meaning of
6. Especially in contemporary art, there are many works similar to 'Cow Tools' where even the appropriate audience is completely in the dark regarding the meaning. Here is just one example: 'A distance separates object from argument in Ghada Amer's Untitled (John Rose). Her paintings look, the catalogue concedes, "like finely drawn, delicate abstractions". The informed eye leads one to surmise that her work shows the influence of Cy Twombly. But as with Calame's work, the eye is a very poor guide to what we in fact see. First, the lines are not drawn or painted but sewn. Second, the forms are not abstract but derived from images of women in pornographic magazines. One can once instructed, see that these are stitchings, but I found it as difficult to make out that I was looking at "sexually suggestive postures" as I did to identify as female body parts cut from the same genre of magazines the things with which the Holy Virgin Mary is surrounded in Chris Ofili's controversial painting from the Brooklyn "Sensation" show. In any case, Amer is making, by means of stitched prurient imagery, some statement about the representation of women. One would not know this without help' (Danto 2005). 
7. According to

Levinson, for instance, 'the core meaning of a literary work is given by the best hypothesis, from the position of an appropriately informed, sympathetic and discriminating reader, of authorial intent' (Levinson 1999: 14). the word 'Rosebud'. In the very last scene of the movie we get to see what 'Rosebud' refers to, but it is still up to us to interpret this surprising image. The ending makes such a strong impression precisely because we gradually come to grasp the full meaning of this revelation. A child who is unable to make the right interpretation may ask us to explain what it is all about and our explanation may give her some idea, but the film will definitely not have the same effect on her as it had on us.

Of course, not all works of art depend on a similar 'punchline mechanism' (landscape paintings, portraits, etc.), and those that do are usually not completely dependent on it (there are so many other elements in Citizen Kane that make it a great movie). Still, it is enough that some aspects of some artworks can be understood along these lines to see the relevance of the above analysis.

Just like jokes and cartoons, art-with-a-punchline will not have the desired effect if the audience is unable to solve the puzzle posed by the work of art. Naturally, this does not imply that the work is a failure. The fact that a child spectator is unimpressed by Citizen Kane does not mean that there is something wrong with the film. There is rather something wrong with the spectator, or, to put it more accurately, children are not the appropriate audience for a film like Citizen Kane. Similarly, when you tell a mathematics joke to an audience that does not know anything about mathematics and the joke falls flat, that does not mean that the joke is bad. However, if you tell the mathematics joke to an audience of mathematicians who have all the relevant background information, and even they do not understand the joke, then we would probably conclude that there is something wrong with the joke. This, I want to argue, is exactly what happened with 'Cow Tools'. If even '40-odd professionals with doctoral degrees in disparate disciplines' and 'Fellows from every walk of American Life, who have been drawn together by a need to know' do not understand what the cartoon is about, then the natural conclusion is that something went wrong with the cartoon. Larson himself comes to this conclusion. He does not blame the audience for their perplexity, he blames himself. He should have made the point of 'Cow Tools' more clear. 'Nothing', he says, 'is perhaps more frustrating in this business than to open a newspaper, turn to your own little creation, and discover that some idiot has screwed it all up, and discover that that idiot was you [original emphasis]' (Larson 1989: 121).

All this demonstrates that some insights and aspects of hypothetical intentionalism are worth keeping and can be of use to the actual intentionalist. Firstly, we should hold on to the notion of the appropriate audience a notion that plays no role in partial intentionalism, but is a key ingredient of hypothetical intentionalism. ${ }^{7}$ That notion is important, but not so much because it is crucial in determining the meaning of a work, but because it is crucial to its evaluation and appreciation. If a joke, cartoon or artwork-witha-punchline does not have the desired effect, we need the notion of an appropriate audience to determine whether the problem lies with the audience or with the work itself.

Secondly, where jokes, cartoons or art-with-a-punchline are concerned, the hypothetical intentionalist is perfectly right in claiming that ' $[\mathrm{t}]$ he work, if any good, will stand on its own, without the author on hand to explain regularly what he meant' (Levinson 1996: 206). The hypothetical intentionalist is 
wrong, however, in thinking that this holds for all works of art and that it is 'a ground rule' for determining work meaning 'that direct authorial pronouncements of meaning can be set aside by the reader' (Levinson 1996: 208). Even in the example of 'Cow Tools', a cartoon that is justly considered a failure because it cannot 'stand on its own', readers consider direct authorial pronouncements highly relevant for the meaning of the work.

(iii) Most people would see Larson's intentions regarding the implicit content of 'Cow Tools' as partly constitutive of the cartoon's meaning. Livingston's partial intentionalism can account for this. Larson's intentions are not only compatible with the features of the cartoon as a whole, they also mesh sufficiently with those features, in every sense of the word. They bear a 'meaningful, integrative relation with them' and open up 'previously undetected connotations'. So, Livingston's success condition is fully satisfied. Nevertheless, a problem seems to arise. For isn't it rather awkward to say that Larson's intentions were successfully realized in the case of 'Cow Tools'? Indeed, Larson would be the first to admit that they were not. So, we seem to come to a paradoxical conclusion: Larson did not successfully realize his intentions, but his intentions are nonetheless partly constitutive of the cartoon's meaning.

One way to go from here would be to accept this as a fact and give up the project of finding success conditions for intentions. Intentions, one might argue, simply do not need to be successfully realized in order to be (partly) constitutive of work meaning. ${ }^{8}$

Another, and in my view more promising response would be to hold on to the idea that intentions can only be constitutive of work meaning if they are successfully realized, and to argue that the paradox is the result of confusing different kinds of intentions. As Donald Davidson points out in 'Locating Literary Language': 'we can speak of "the" intention with which an act is performed only by narrowing attention to one among the tangle of intentions involved in any performance' (Davidson 2005: 170). A particularly useful distinction in this regard is the distinction between the intention to say something and the intention to communicate something. Stecker makes this distinction to clarify what happens in malapropisms like 'There's a fly in your suit' (Stecker 2004: 11). Here, he says, the intention to communicate is successful, but the intention to say something is not. In 'Cow Tools', one might argue, the opposite is true. Here we have an unsuccessful intention to communicate, though we might agree that the cartoon actually means what Larson intended it to mean. Thus, Larson's intention to create a meaningful cartoon is successful, but his intention to get his point across and make people laugh is not, which explains his dissatisfaction with the result.

\section{V.}

According to Livingston, the artist's intentions are successfully realized and hence determinant of the meaning of a work if and only if they are compatible and 'mesh' with the linguistic and conventional meanings of the text or artefact taken in its target or intended context. In this paper I have tried to show that this specific standard of success is not without its difficulties. First, I have argued that an artist's intention can sometimes be constitutive of a work's meaning even if there is no significant meshing between the artist's intention and his work. Secondly, I have contested the apparently
8. If this seems a strange idea, think of actions. Intentions often determine the meaning of an action, even if the intentions are not successfully realized ('He was stealing, but fortunately we caught him before he took anything valuable'). Livingston's own distinction between executing and realizing an intention may also be helpful here (Livingston 2005: 11). 
9. I am very grateful to Rafael De Clercq, Jonathan Friday, Jeremy McKenna, Michael Newall, Jerrold Levinson and Paisley Livingston for helpful comments on earlier versions of this paper. uncontroversial claim that the artist's intentions need to be compatible with the linguistic and conventional meanings of a text. Thirdly, I have presented a case that creates a puzzle for the partial intentionalist because the intentions of the artist concerned are not successfully realized, though they are compatible and mesh with all the relevant data. I have concluded my paper by suggesting a solution to this puzzle.

This paper does not show that the project of moderate actual intentionalism is fatally flawed. As I indicated at the beginning of my essay, I am actually convinced that moderate actual intentionalism is superior to most rival views, including hypothetical intentionalism. Nevertheless, I have argued that some aspects of hypothetical intentionalism, in particular the notion of the appropriate audience, can be of use to the partial intentionalist and should be retained in the further elaboration of partial intentionalism. Furthermore, I believe that the objections I have raised do pose genuine difficulties for the partial intentionalist - difficulties that need to be overcome in order to arrive at a truly convincing account of the specific role of the artist's intention in the interpretation of art. ${ }^{9}$

\section{References}

Carroll, N. (1991), 'On Jokes', Midwest Studies in Philosophy, 16, pp. 280-301.

Danto, A. C. (2005), Unnatural Wonders, New York: Farrar, Straus and Giroux.

Davidson, D. (2005), Truth, Language, and History, Oxford: Oxford University Press.

Davies, S. (2006), The Philosophy of Art, Oxford: Blackwell.

Iseminger, G. (1996), 'Actual Intentionalism vs. Hypothetical Intentionalism', Journal of Aesthetics and Art Criticism, 54: 4, pp. 319-326.

Larson, G. (1989), The PreHistory of The Far Side: A 10th Anniversary Exhibit, London: Warner Books.

Levinson, J. (1996), The Pleasure of Aesthetics, Ithaca: Cornell University Press.

Levinson, J. (1999), 'Two Notions of Interpretation', in Haapala, A. and Naukkarinen, O. (eds), Interpretation and its Boundaries, Helsinki: Helsinki University Press, pp. 2-21.

Livingston, P. (2005), Art and Intention: A Philosophical Study, Oxford: Clarendon.

Stecker, R. (2003), Interpretation and Construction: Art, Speech, and the Law, Oxford: Blackwell.

Wollheim, R. (1987), Painting as an Art, Princeton: Princeton University Press.

\section{Suggested citation}

Maes, H. (2008), 'Challenging partial intentionalism', Journal of Visual Arts Practice 7: 1, pp. 85-94, doi: 10.1386/jvap.7.1.85/1

\section{Contributor details}

Hans Maes is Postdoctoral Researcher and Sessional Lecturer at the University of Kent at Canterbury, UK. He received his PhD from the University of Leuven, Belgium, and conducted postdoctoral research at the University of Helsinki, Finland, and University of Maryland, USA. His main research interests are aesthetics, philosophy of photography and film, moral psychology.

Contact: History and Philosophy of Art, Eliot College, University of Kent, Canterbury, UK, CT2 $7 \mathrm{NZ}$, 01227824871.

E-mail: H.Maes@kent.ac.uk 
Copyright of Journal of Visual Art Practice is the property of Intellect Ltd. and its content may not be copied or emailed to multiple sites or posted to a listserv without the copyright holder's express written permission. However, users may print, download, or email articles for individual use. 